\title{
Innovative Periodontal Surgery by Monocortical Corticotomy in Management of Bimaxillary Protrusion Cases: A Clinical Study
}

\author{
${ }^{1}$ Mohinder Panwar, ${ }^{2}$ Dhruv Dubey, ${ }^{3}$ Manab Kosala
}

\begin{abstract}
Periodontal accelerated osteogenic orthodontics (PAOO) is a procedure applying the clinical science of alveolar corticotomy, particulate bone grafting, and the application of orthodontic forces, for accentuated tooth movement. This is theoretically based on the bone healing pattern known as the regional acceleratory phenomenon (RAP).

A series of 12 cases, including 8 females and 4 males, were included in the study. The cases were referred from the Department of Orthodontia to the Department of Periodontology, ADC (R\&R), having bimaxillary protrusion with an increased overjet. After initial orthodontic alignment, buccal corticotomy procedure was planned. A full-thickness mucoperiosteal flap was reflected from maxillary canine to canine beyond the root apices. Vertical corticotomy cuts were given in the alveolar bone with piezo blades $2 \mathrm{~mm}$ apical to the crestal bone in the inter-radicular space midway between the root prominences and were joined by the horizontal cuts apically. Demineralized freeze-dried bone allograft (DFDBA) was placed in the surgical area. The flaps were sutured and pack was placed. Orthodontic retraction was started 2 weeks after the corticotomy procedure.

Using this procedure, the treatment objectives were met in just half to one-third of the reported conventional treatment time and the large overjet was reduced to normal. Pre- and posttreatment clinical parameters were recorded, statistically analyzed, and corroborated with similar orthodontic treatment procedures without the use of the corticotomy technique.

The present periodontal (PDL) intervention results in quick and stable results for the correction of bimaxillary protrusion cases. It enhances the esthetics and posttreatment orthodontic stability.
\end{abstract}

Keywords: Demineralized freeze-dried bone allograft, Periodontal accelerated osteogenic orthodontics, Regional acceleratory phenomenon.

How to cite this article: Panwar M, Dubey D, Kosala M. Innovative Periodontal Surgery by Monocortical Corticotomy in Management of Bimaxillary Protrusion Cases: A Clinical Study. Int J Experiment Dent Sci 2017;6(2):55-60.

Source of support: Nil

Conflict of interest: None

\footnotetext{
${ }^{1,3}$ Associate Professor, ${ }^{2}$ Graded Specialist

1,3 Department of Periodontology, Armed Forces Medical College Pune, Maharashtra, India

${ }^{2}$ Department of Periodontology, Military Dental Center Ahmednagar, Maharashtra, India
}

Corresponding Author: Mohinder Panwar, Associate Professor Department of Periodontology, Armed Forces Medical College Pune, Maharashtra, India, e-mail: mpanwar2003@gmail.com

\section{INTRODUCTION}

The conventional view of orthodontic tooth movement is that of a cell-mediated process orchestrated predominantly within the PDL ligament. Sustained force on a tooth translates into a PDL cell population, resulting in the conversion of pleomorphic fibroblasts into osteoblasts, osteoclasts from monocytic precursors. This results in the osteoclasis of the lamina dura, massive cell death, and hyalinization within the PDL followed by frontal resorption and bone deposition, leading to the desired tooth movement.

Periodontal accelerated osteogenic orthodontics is a procedure combining selective alveolar corticotomy, particulate bone grafting, and the application of orthodontic forces. The procedure, theoretically based on the bone healing pattern known as the RAP, was developed by Thomas Wilcko (periodontist) and William Wilcko (orthodontist) in 1995. ${ }^{1}$ Following surgical wounding of cortical bone, RAP potentiates tissue reorganization and healing by way of a transient burst of localized hard and soft tissue remodeling. The RAP in humans begins within a few days of surgery, typically peaks at 1 to 2 months, and may take from 6 to more than 24 months to subside.

Kole $^{2}$ first reported combining orthodontics with corticotomy surgery and completed the active tooth movement in adult orthodontic cases in 6 to 12 weeks. Frost, ${ }^{3}$ an orthopedist, in the year 1989 documented that surgical wounding of osseous hard tissue results in striking reorganizing activity adjacent to the site of injury in osseous and/or soft tissue surgery. Gantes et al ${ }^{4}$ carried out preliminary studies on corticotomy-assisted orthodontic tooth alignment. According to them, the mean treatment time was 14.8 months for the experimental group (corticotomy) and 28.3 months for the control group (without corticotomy). Suya ${ }^{5}$ reported desirable tooth movements by moving blocks of bone using the crowns of the teeth as handles.

\section{CLINICAL CASES}

A total of 12 cases were studied over 18 months. These included 4 males and 8 females in the age group of 15 to 25 years $(21.33 \pm 2.12$ years). The cases were referred from the Department of Orthodontia to the Department 
of Periodontology, ADC (R\&R), having bimaxillary protrusion with an increased overjet (Figs 1A to C). Informed consent of the subjects and clearance from Ethical Clearance Committee of the institution was taken. This was followed by a detailed medical and dental case history. The inclusion criteria were set at systemically and periodontally healthy individuals who were motivated for the treatment and postoperative maintenance. Exclusion criteria were defined as individuals who were smokers, had parafunctional habits, were on any medications, pregnant females, and those who gave any previous history of PDL surgery.

Six patients (group I) were treated with the PAOO technique, and six patients (group II) were treated by conventional nonsurgical orthodontics. The patients in each of the group were randomly selected to rule out any bias.
The study was aimed at evaluation of the efficacy of monocortical corticotomy as an adjunct to the conventional orthodontic therapy, in treatment of bimaxillary protrusion cases, and to statistically compare the periodontally assisted orthodontic procedure to the conventional orthodontic procedures.

Clinical parameters, namely the arch length and overjet, were recorded at baseline and at the completion of the treatment. Periodontal parameters, namely probing depth (PD), clinical attachment level (CAL), width of attached gingiva (AG), were recorded at baseline, 6 months, and at the end of 18 months.

In group I cases, initial orthodontic teeth alignment and leveling of $\mathrm{U} / \mathrm{L}$ anterior teeth was carried out using a 014" and 016" NiTi wire (for 1 month) (Fig. 1D). After 4 weeks of alignment, the cases were referred to the
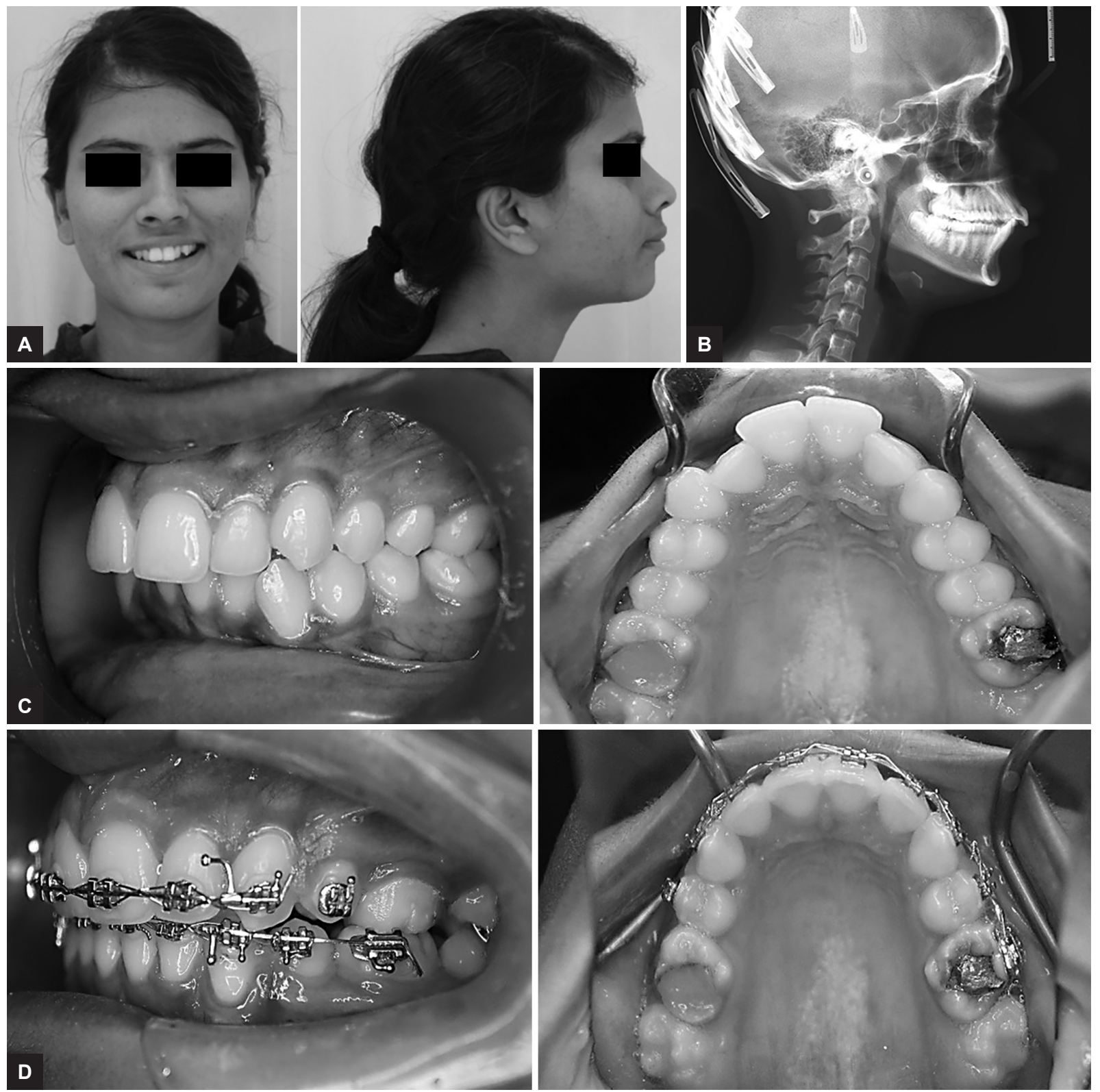

Figs 1A to D: Preoprative (A) Front and side lateral profile; (B) lateral cephalogram; (C) intraoral examination; and $(D)$ initial orthodontic leveling 
Department of Periodontology. Surgical corticotomy procedure was planned only involving the labial cortical plates in the upper and lower anterior region. Routine blood hemogram, urine examination, and blood sugar estimation were done prior to the surgical procedure. Extra- and intraoral antisepsis was carried out, and the surgical site was anesthetized using $2 \%$ lignocaine solution with adrenaline. A full-thickness mucoperiosteal flap was reflected from maxillary canine to canine beyond the root apices. Monocortical vertical corticotomy cuts were given in the alveolar bone with piezo blades $2 \mathrm{~mm}$ apical to the crestal bone in the inter-radicular space mid-way between the root prominences, and extended 1 to $2 \mathrm{~mm}$ apically beyond the apex of the roots (Fig. 2A). The vertical cuts were joined by similar horizontal piezo cuts apically. Solitary perforations were made in the alveolar bone over the radicular surface, aimed at release of growth factors and mediators of inflammation, and graft incorporation. The DFDBA was placed in the surgical area and the flaps were sutured (Fig. 2B). A periodontal pack was placed to secure the surgical site and aid the patient comfort. Similar procedure was carried out in the mandibular arch from canine to canine region (Figs $2 \mathrm{C}$ and D). Postoperative antibiotics and analgesics were prescribed, and instructions were imparted to the patients. Suture removal was done 1 week after the surgical procedure. All the cases reported uneventful healing.

Orthodontic retraction was started 2 weeks after the corticotomy procedure. Initial retraction was established by rectangular $0.017 \times 0.025$ stainless steel arch wire with 250 to $300 \mathrm{gm}$ force ( 2 weeks after the corticotomy procedure). En mass retraction using sliding mechanics with the help of a closed coil spring (4-6 months).

\section{DATA ANALYSIS}

Statistical analysis was performed using the Wilcoxon test for a paired group comparison (Table 1). The treated area was the unit of analysis. Pre- and postoperative measurements of each parameter were averaged [mean \pm standard deviation (SD)], and all tests were performed at the $5 \%$ significance level; $p$-values $<0.05$ were regarded as statistically significant.

\section{RESULTS}

Pre- and posttreatment periodontal parameters were recorded, statistically analyzed, and corroborated with similar orthodontic treatment procedures without the use of the corticotomy technique (Table 2).

An effective and desirable treatment result was obtained in all the subjects using the PAOO technique, within an average time span of 6 to 8 months (Fig. 3).

A comparative clinical and radiographical preoperative and the postoperative assessment is presented in Fig. 4.
Using this procedure the treatment objectives in group I cases were met in just half to one-third of the treatment time required by conventional orthodontics in group II cases (net treatment time: Group I $208.50 \pm$ 20.125 days and group II $546 \pm 11.246$ days) (Table 1 ). These results were statistically significant ( $p$-value $<0.05$ ).

Statistically significant reduction in overjet values were recorded between the two groups (group I $5.36 \pm$ $0.976 \mathrm{~mm}$ and group II $4.95 \pm 1.156 \mathrm{~mm}$ ) (Table 1).

Statistical analysis of regaining of arch length was nonsignificant ( $p$-value $>0.05$ ) (Table 1). Furthermore, nonsignificant results were arrived at comparing the periodontal parameters ( $\mathrm{PD}, \mathrm{CAL}$, and $\mathrm{AG}$ ) between the test and the control groups (Table 2).

\section{DISCUSSION}

Periodontally accelerated osteogenic orthodontics can play an important role in the comprehensive treatment of patients' occlusal and esthetic needs, as this procedure has shown optimal results regarding increased alveolar bone thickness, decreased treatment time, reduced patient discomfort of long-term use of brackets, and also increased long-term stability of the orthodontic treatment with healthy periodontium. It can be observed from the study that surgical corticotomy reduces the treatment time by almost one-third when compared with the conventional orthodontic procedure. These results are in accordance with the results of the study done by Wilcko et $\mathrm{al}^{6}$ in which the corticotomy procedure has reduced the treatment time and the teeth moved three to four times faster than the conventional orthodontics. According to Wilcko et $\mathrm{al}_{,}{ }^{6}$ it is the placement of the bone graft which is an additional step that is believed to be responsible for the increased posttreatment stability and increased alveolar bone width as well as maintainable periodontium. It has been documented that trauma to cortical bone potentiates localized osteoporosis, increased mobilization of calcium, decreased bone density, and increased bone turnover that potentiates rapid tooth movement. ${ }^{7}$ According to Suya, ${ }^{5}$ the protein extracts from the decalcified bone matrix are responsible for the new bone formation.

\section{CONCLUSION}

Periodontally accelerated osteogenic orthodontics facilitates the orthodontist to get the treatment done with decreased treatment time, i.e., in traditional orthodontic treatment it takes about 1.5 to 2 years, whereas by doing PAOO, movement of tooth is obtained within 6 to 8 months. It enhances the esthetics and posttreatment orthodontic stability. It increases the access of the 

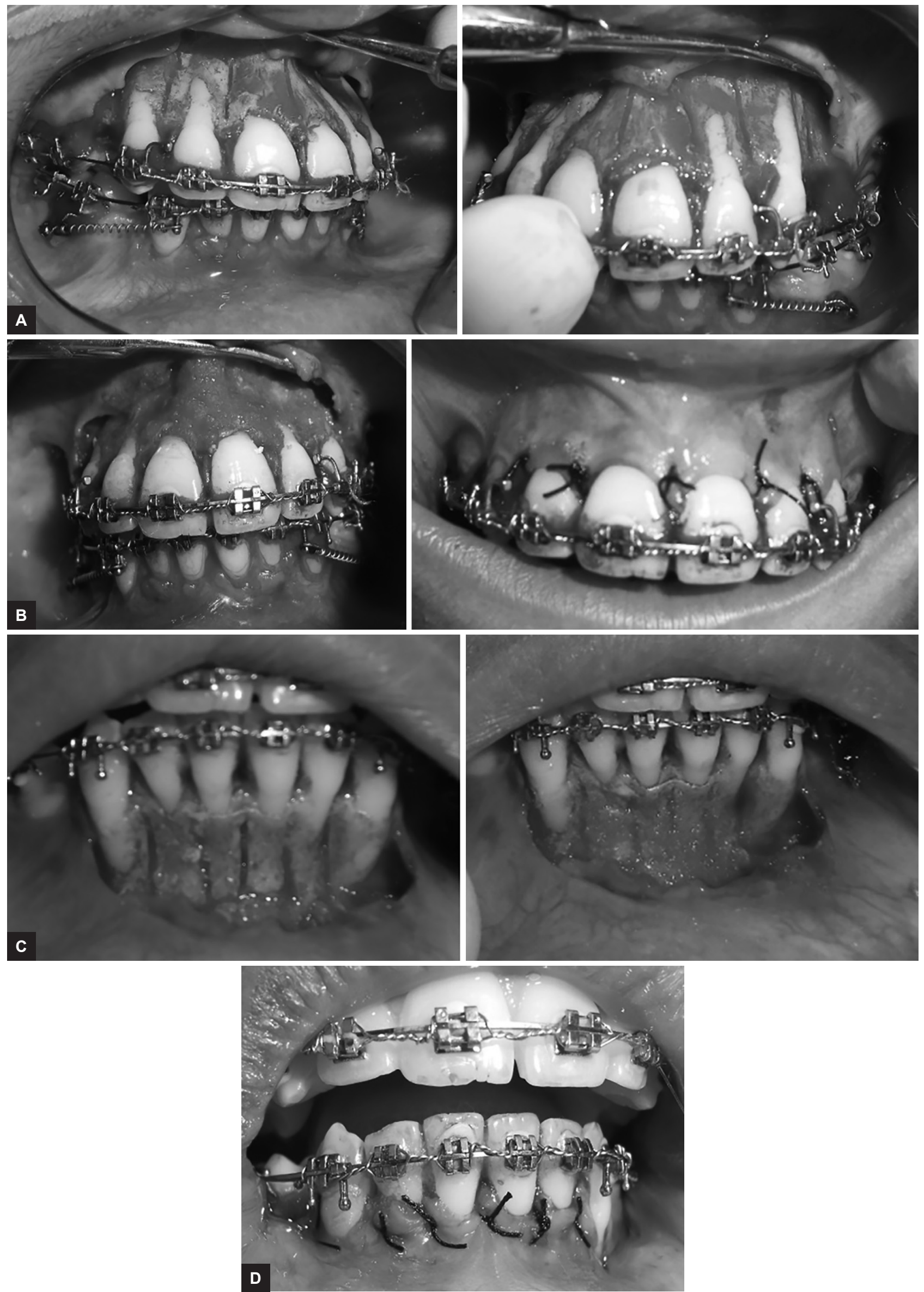

Figs 2A to D: Intraoperative. (A) Maxillary anterior monocortical corticotomy using piezo unit; (B) maxilla: allograft (DFDBA) placement and wound closure; (C) mandible: monocortical corticotomy and allograft placement; and (D) mandible: wound closure 
Innovative Periodontal Surgery by Monocortical Corticotomy

Table 1: Wilcoxon test for a paired group comparison

\begin{tabular}{lll}
\hline Parameters & Mean $\pm S D$ & p-value \\
\hline Regaining in arch length & & \\
Group I & $7.35 \pm 1.104 \mathrm{~mm}$ & NS \\
Group II & $7.04 \pm 1.67 \mathrm{~mm}$ & \\
Reduction in overjet & \\
Group I & $5.36 \pm 0.976 \mathrm{~mm}$ & 0.042 \\
Group II & $4.95 \pm 1.156 \mathrm{~mm}$ & \\
Net treatment time & & \\
Group I & $208.50 \pm 20.125$ days & 0.001 \\
Group II & $546 \pm 11.246$ days & \\
\hline
\end{tabular}

SD: Standard deviation; NS: Not significant

Table 2: Statistical analysis: Periodontal parameters

\begin{tabular}{|c|c|c|c|c|c|c|}
\hline \multirow{2}{*}{$\begin{array}{l}\text { Time of } \\
\text { comparison }\end{array}$} & \multicolumn{2}{|c|}{ Group I } & \multicolumn{2}{|c|}{ Group II } & \multirow[b]{2}{*}{$t$-value } & \multirow[b]{2}{*}{$p$-value } \\
\hline & Mean & $S D$ & Mean & $S D$ & & \\
\hline \multicolumn{7}{|l|}{$P D(m m)$} \\
\hline Baseline & 1.10 & \pm 0.307 & 1.15 & \pm 0.366 & 0.467 & $0.643 \mathrm{NS}$ \\
\hline 6 months & 0.90 & \pm 0.205 & 0.90 & \pm 0.205 & 0 & $0.643 \mathrm{NS}$ \\
\hline 18 months & 1.00 & \pm 0.512 & 0.97 & \pm 0.302 & 0.188 & $0.852 \mathrm{NS}$ \\
\hline \multicolumn{7}{|l|}{$C A L(m m)$} \\
\hline Baseline & 4.85 & \pm 1.531 & 5.20 & \pm 1.151 & 0.817 & $0.419 \mathrm{NS}$ \\
\hline 6 months & 2.35 & \pm 1.170 & 1.90 & \pm 0.640 & 1.508 & $0.140 \mathrm{NS}$ \\
\hline 18 months & 2.52 & \pm 1.186 & 2.20 & \pm 0.732 & 1.042 & $0.304 \mathrm{NS}$ \\
\hline \multicolumn{7}{|l|}{$A G(m m)$} \\
\hline Baseline & 2.32 & \pm 0.921 & 2.00 & \pm 0.668 & 1.276 & $0.210 \mathrm{NS}$ \\
\hline 6 months & 3.20 & \pm 0.978 & 3.50 & \pm 1.112 & 0.906 & $0.371 \mathrm{NS}$ \\
\hline 18 months & 3.27 & \pm 0.952 & 3.62 & \pm 1.244 & 0.999 & $0.324 \mathrm{NS}$ \\
\hline
\end{tabular}


Figs 3A and B: Postoperative 6 months: (A) Front and side lateral profile; and (B) lateral cephalogram
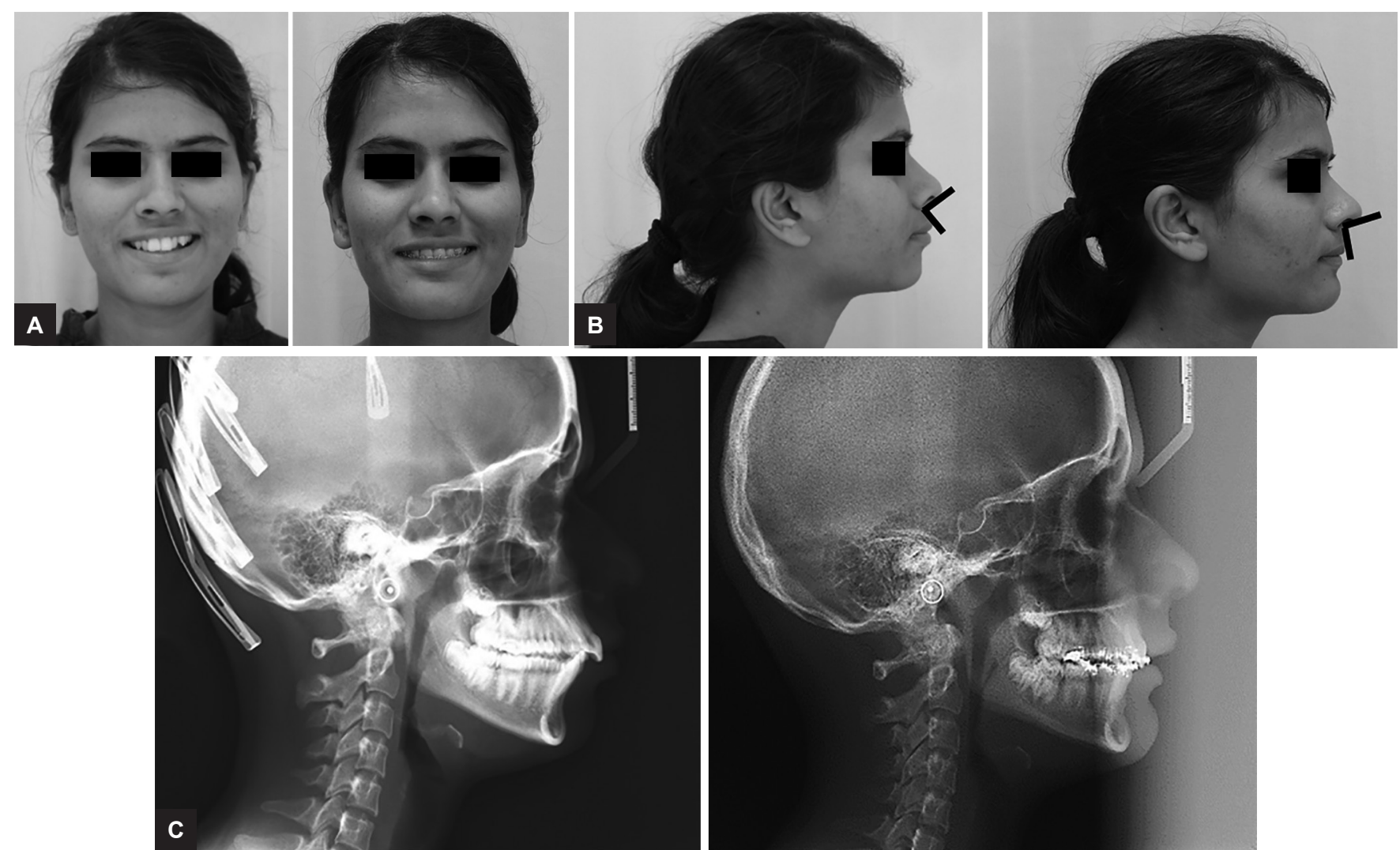

Figs 4A to C: Pre- and postoperative comparison: (A) Frontal profile; (B) side lateral profile; and (C) lateral cephalogram 
patient toward orthodontic therapy. Other applicable advantages of the PAOO technique include nonextraction management of moderately severe crowding by increasing the alveolar volume without causing labial tipping, reduced relapse rate, and physiological tooth movement without bone necrosis. Except for severe class III skeletal dysplasia, PAOO can replace some orthognathic surgery, and because of the low morbidity, patients 11 to 78 years old have been treated with marked success. The major disadvantage of the procedure is postoperative patient morbidity. The success of this treatment depends on the coordination of the orthodontist, periodontist, and oral and maxillofacial surgeon.

\section{REFERENCES}

1. Wilcko WM, Wilcko MT, Bouquot JE, Ferguson DJ. Rapid orthodontics with alveolar reshaping: two case reports of decrowding. Int J Periodontics Restorative Dent 2001 Feb;21(1):9-19.

2. Kole H. Surgical operations on the alveolar ridge to correct occlusal abnormalities. Oral Surg Oral Med Oral Pathol 1959 May;12(5):515-529.

3. Frost HM. The biology of fracture healing: an overview for clinicians part II. Clin Orthop Rel Res 1989 Nov;248:283-289.

4. Gantes B, Rathbun E, Anholm M. Effects on the periodontium following corticotomy-facilitated orthodontics. Case reports. J Periodontol 1990 Apr;61(4):234-238.

5. Suya, H. Corticotomy in orthodontics. In: Hosl E, Baldauf A, editors. Mechanical and biological basis in orthodontic therapy. Heidelberg (Germany): Huthig Buch Verlag; 1991.

6. Wilcko WM, Wilcko T, Bissada NF. An evidence based analysis of periodontally accelerated orthodontic and osteogenic techniques: a synthesis of scientific perspectives. Semin Orthod 2008 Dec;14(4):305-316.

7. Hajji, SS. the influence of accelerated osteogenic response on mandibular de-crowding [thesis]. St Louis (MO): St Louis University; 2000. 